\title{
MÉTRICA Y PRONUNCIACIÓN EN EL LIBRO DE BUEN AMOR: PROTOTIPO DEL ISOSILABISMO CASTELLANO MEDIEVAL
}

\author{
Francisco P. Pla COLOMER \\ Universität Augsburg
}

\section{El Libro de Buen Amor en su contexto filológico}

Desde la publicación en 1913 de la edición de Julio Cejador, todavía no se han alcanzado resultados unánimes en lo concerniente a la métrica del Arcipreste. Mientras algunos estudiosos consideran que Juan Ruiz tendía a regularizar la métrica de sus versos en estrofas híbridas, otros sostienen el carácter anisosilábico de sus poemas, tesis inserta en la corriente literaria fundamentada en la consideración irregular de las composiciones poéticas castellanas de la Baja Edad Media (desde los primeros poemas del mester de clerezia hasta los correspondientes a la generación de los Reyes Católicos). En 1967 ve la luz la edición preparada por Joan Corominas, quien, desde una perspectiva filológica integral, concluye que Juan Ruiz buscaba la regularidad silábica, caracterizada por la distribución equitativa de versos alejandrinos octosílabos y heptasílabos en estrofas homogéneas. Además de colacionar los manuscritos en un proceso ecdótico riguroso, su edición tuvo como fundamento la combinación de la métrica y el análisis lingüístico como herramientas filológicas válidas para reconstruir el texto original'

${ }^{1}$ «La monumental edición crítica, por J. Corominas, del Libro de Buen Amor muestra que el esfuerzo más valioso realizado por el editor es el dirigido a aclarar el texto desde un punto 
A partir de la estrecha relación existente entre el componente fónico de la lengua, que «con el paso del tiempo necesita de la filología para su interpretación $»^{2}$, de un lado, y la métrica y rima de los textos poéticos ${ }^{3}$, de otro, parece conveniente abordar la materialidad del texto juanruiciano según la articulación del castellano en época de Alfonso Onceno (1312-1350). Desde los estudios clásicos de Navarro Tomás ${ }^{4}$, Dámaso Alonso y Lapesa ${ }^{5}$, la métrica y la rima han constituido instrumentos filológicos esenciales para inferir los rasgos evolutivos del componente fónico del castellano.

En 1962 Dámaso Alonso ${ }^{6}$ recurrió a las rimas de poetas cuyas composiciones se insertan en el período que abarca desde finales de la Edad Media hasta el siglo XVII, con la finalidad de reconstruir el proceso de desfonologización de los fonemas bilabiales sonoros en posición intervocálica. Anteriormente al estudio emprendido por Dámaso Alonso, Rafael Lapesa había acudido ya en 1953 al estudio de las rimas del Cancionero de Baena para arrojar luz sobre los híbridos lingüísticos gallego-castellanos que caracterizan la lengua de dichas composiciones.

El estudio de la disposición acentual y la relación establecida entre las sílabas de los versos de una determinada métrica, conjuntamente con el análisis de la rima, permite reconstruir los rasgos fónicos del castellano en sus diversas etapas 7 , razón por la que la descripción de la fonética y fonología castellanas en su perspectiva diacrónica, junto a la caracterización de los rasgos métricos correspondientes al segundo ciclo del mester de clerezia, permitirá arrojar luz al presunto isosilabismo del Libro de Buen Amor, principalmente en contraste con el análisis de otros textos poéticos castellanos medievales. Para ello, se precisa

de vista lingüístico. La riqueza léxica del Buen Amor y la complejidad sintáctica de sus versos invitan, claro está, a interpretaciones divergentes; pero el sistemático comentario verso a verso, realizado por Corominas, representa una paso adelante muy marcado en el esclarecimiento de los problemas pendientes» (D. Catalán, Lingüística Íbero-románica. Crítica retrospectiva, Gredos, Madrid, 1974, pág. 206).

${ }^{2} \mathrm{M}$. T. Echenique, «Fuentes y vías metodológicas para el estudio de la pronunciación castellana a través de su historia. De Amado Alonso al siglo XXI», en M. T. y F. J. Satorre (eds.), Historia de la pronunciación de la lengua castellana, Tirant lo Blanch, Valencia/Neuchâtel, 2013, pág. 30.

${ }^{3}$ M. T. Echenique y F. P. Pla Colomer, «Reconstrucción fonética y periodización a la luz de la métrica y la rima», en M. T. Echenique y F. J. Satorre (eds.), loc. cit., págs. 61-104.

${ }_{4}$ Véase T. Navarro Tomás, Manual de pronunciación española, CSIC, Madrid, ${ }^{2} 1972$, y Los poetas en sus versos: desde Jorge Manrique a García Lorca, Ariel, Barcelona, 1973.

${ }_{5}$ Véase R. Lapesa, «Sobre el ceceo y el seseo andaluces», en Estudios de la historia lingüistica española, Paraninfo, Madrid, 1985, págs. 249-266.

${ }^{6}$ D. Alonso, «Temas y problemas de la fragmentación fonética peninsular», Obras completas, I: Estudios lingüísticos peninsulares, Gredos, Madrid, ${ }^{21972, ~ p a ́ g s . ~ 13-291 . ~}$

${ }^{7}$ «For this reason, the study of specific verse prosodies can shed some light on the rhythmic principles that underline the corresponding speech prosodies and [...] the ways in which different languages parameterise and articulate the general rhythmic capacities» (R. Rodríguez-Vázquez, The Rhythm of Speech, Verse and Vocal Music: A New Theory, Peter Lang, Berna, 2010, pág. 165). 
subrayar los límites cronológicos de la escuela del mencionado mester de clerezia (como ya hicieron en su día G. Hilty ${ }^{8}$ I. Uría9) que, seguramente, sobrepasara los límites cronológicos del siglo XIII y alcanzó, a modo de aprendizaje teórico-práctico inserto en el programa educativo del trivium, a los poetas del siglo XIV ${ }^{10}$. La clerezia, por tanto, fue un saber adquirido mediante el aprendizaje de las artes liberales, especialmente la lengua, la gramática, la retórica y la dialéctica ${ }^{11}$. Junto a los conocimientos del latín y el saber metrificar, el mérito de estos poetas fue el de saber rimar y leer la nueva estrofa o vía, como queda personificado en la figura de Tarsiana en el Libro de Apolonio, una poeta ocasional y letrada que cuenta su propia vida en romance bien rimado.

Desde este punto de vista, obras como la Vida de San Ildefonso, el Libro de miseria de omne, el Libro de Buen Amor, los Proverbios morales de Sem Tob y el Rimado de Palacio, entre otros, constituyen un conjunto de poemas insertos en un segundo ciclo de esta escuela, más innovador y abrupto, reflejo de un siglo en crisis y de innovadores rumbos culturales.

\subsection{La corte de Alfonso Onceno: nuevo modelo cultural}

El efecto de la Peste Negra, el continuo avance de la Reconquista y el desarrollo de las complicadas relaciones del reino de Castilla con Aragón y Portugal, fueron factores que desembocaron en una generalizada crisis demográfica. En los nuevos entornos sociales el descontento de la nobleza era un hecho sobresaliente, por pensar que carecían del poder económico correspondiente a su estatus social. En esta misma línea, la legislación vigente desde el reinado de Alfonso X daba prioridad al papel regio por encima de cualquier otro estamento, hecho que suscitó querellas y disputas sociales hasta ser finalmente solventadas por Alfonso Onceno en el Ordenamiento de Alcalá de 1348, texto que supuso la redefinición de los procesos judiciales y la legislación regia entendida, según investigaciones recientes, como la unión feudal entre la

${ }^{8}$ G. Hilty, «La figura del juglar en la Castilla del siglo XIII», Versants, 28, 1995, págs. 153-173.

${ }^{9}$ I. Uría, Panorama critico del mester de clerecia, Castalia, Madrid, 2000.

${ }^{10} \mathrm{R}$. Willis («Mester de clerecía. A Difinition of the Libro de Alexandre», Romance Philology, 10, 1956-1957, págs. 212-224) y A. Deyermond (Historia de la literatura española 1, La Edad Media, Ariel, Barcelona, 2003) niegan, sobre la base de la estrofa 2 del Libro de Alexandre, que en ella se contengan los rasgos formales de una escuela poética nueva. En la misma línea, A. Gómez («La poesía épica y de clerecía medievales», en A. Gómez y C. Alvar (eds.), Historia crítica de la Literatura Hispánica, 2, Taurus, Madrid, 1988) cree que no es pertinente hacer uso del rótulo mester de clerezia para referirse a una escuela poética; en su lugar emplea la fórmula cuaderna vía, bajo la que incluye todos los poemas compuestos por este molde estrófico en los siglos XIII y XIV. Al igual que I. Uría (op. cit.), comparto la idea de que los poetas de la presente centuria formaban parte del mismo círculo universitario que, seguramente, se insertaba en una escuela panrománica, como ya había señalado F. Rico («La clerecía del mester», Hispanic Review, 1, 1985, págs. 1-23, y 2, 1985, págs. 127-150).

${ }^{11}$ C. Moreno, «Amplificatio y Dilatatio en Berceo», Revista de Filología Española, 89, 1., 2009, págs. 83-100. 
monarquía y la fuerza nobiliaria, programa político desarrollado posteriormente por los Trastámara.

La crisis socioeconómica se vio acrecentada por las múltiples guerras que asolaron el Reino de Castilla, como es el caso de los continuos asedios al reino nazarí, algunos de los cuales alcanzaron grandes victorias, como la batalla del Salado (1340), la del río Palmones (1343), la conquista de Algeciras (la primera conquista castellana de consideración después de muchos años) o el asedio de Gibraltar, truncado tras la muerte de Alfonso Onceno. Todo ello, entendido como actos de confirmación de poder regio ${ }^{12}$.

Todos estos avatares socio-culturales formaron parte de una sociedad afectada por profundos cambios religiosos ${ }^{13}$, políticos ${ }^{14} \mathrm{e}$ ideológicos, configuradores del nuevo quehacer literario durante la primera mitad del siglo XIV. La corte letrada de Alfonso Onceno no quedó al margen de esta evolución cultural, sino que participó de manera determinante en proyectos literarios teñidos de naciente espíritu moderno fomentado por el monarca y la nobleza' ${ }^{15}$, tales como la composición de libros de caballería y la producción cronística en prosa y verso.

La labor cultural del rey Justiciero permitió rescatar los valores cortesanos propios de la corriente lírica trovadoresca del siglo XII y, con ello, la recuperación de la tradición caballeresca de autores como Chrétien de Troyes. Comparto la opinión de V. Beltrán ${ }^{16}$, para quien la primera redacción del Amadís de Gaula se llevó a cabo en el seno de la corte de Alfonso Onceno, marco cultural compartido con la aparición del Libro del Cavallero Çifar, pese a las diferencias evidentes entre los dos textos.

${ }^{12} \mathrm{~F}$. Arias, Guerra y fortalecimiento del poder regio en Castilla. El reinado de Alfonso XI (1312-1350), Ministerio de Defensa y CSIC, Madrid, 2012, pág. 42.

${ }^{13}$ Recordemos las recientes palabras de J. A. García de Cortázar (Historia religiosa del Occidente medieval [Años 313-1464], Akal, Madrid, 2012, pág. 395), para quien, entre 1277 y 1464, las imágenes que impulsaron la palabra «crisis» fueron cuatro: «el "atentado de Anagni" contra el papa Bonifacio VIII en 1303, la "cautividad de Babilonia", con la estancia del papado en Aviñón entre 1309 y 1378, el "cisma de Occidente", con la fractura de la obediencia católica y su reparto entre el papa de Roma y el papa de Aviñón entre 1378 y 1417, y el "movimiento conciliarista" que, entre 1417 y 1499, aprovechó las dificultades del pontificado para presentar [...] la opción contractual como forma de gobierno en lugar de la autoritaria».

14 «Las violencias y guerras del período, la emigración dentro del reino, bien hacia el sur, bien hacia las zonas urbanas, los aumentos de tributos o los malos años de cosechas fueron factores que, unidos a la peste, provocaron el indudable retroceso demográfico que se constata en este período en muchos lugares» (E. Manzano, Épocas medievales, Crítica, Barcelona, 2010, pág. 572).

${ }^{15}$ El nuevo modelo regio, renovado posteriormente por los Trastámara (O. Perea, La época del Cancionero de Baena: los Trastámara y sus poetas, Ayuntamiento de Baena y Fundación Pública Municipal Centro de Documentación Juan Alfonso de Baena, Baena, 2009), trajo consigo un aumento de la participación de la nobleza en la corte y la imposición de nuevas tendencias socio-culturales.

${ }^{16}$ V. Beltrán, Edad Media: lírica y cancioneros, Visor Libros, Madrid, 2009. 
En este marco de actuación, los poetas fueron los principales testigos y promotores de los nuevos rumbos intelectuales: mientras el autor del Poema de Alfonso Onceno legitimaba la relación entre el monarca y doña Leonor de Guzmán, el propio rey cantaba sus amores en versos octosílabos castellanos con presencia de léxico galaico-portugués, en el poema En un tiempo cogí flores, composición que pareció influir en el devenir de la poesía castellana. La lírica culta y cortesana aparece tardíamente en castellano; el Libro de Buen Amor constituye, desde esta perspectiva, la primera documentación en la que tienen cabida las composiciones líricas cultas en castellano; los nuevos gustos literarios, los avatares socioculturales y la revolución lingüística permitieron la acomodación de innovadoras estructuras silábicas al metro del octosílabo, así como el empleo de herramientas métricas (sinalefa o compensación silábica de los versos), abandonando, por tanto, los rígidos corsés métricos empleados en los versos de arte menor de la Historia troyana polimétrica. Sin embargo, los vínculos existentes entre poetas castellanos y gallegos desde la centuria precedente originó interferencias entre ambas lenguas ${ }^{17}$; además, el peso de la tradición galaico-portuguesa desembocó en la escuela de poetas portugueses en castellano, tradición que se mantendrá en siglos posteriores:

[...] sin embargo, no siempre se ha tenido en cuenta que los poemas galleguizantes compuestos entre 1360-1425 tuvieron que nacer, con pocas excepciones, como híbridos lingüísticos gallego-castellanos. La mayoría de sus autores eran naturales de Castilla o Andalucía y compusieron sus obras gallegas en territorio de habla castellana ${ }^{18}$.

Asimismo, los rasgos caracterizadores del mester del clerezia se vieron modificados ${ }^{19}$, adecuándose de igual modo a los nuevos gustos culturales que a la evolución fonético-fonológica del castellano ${ }^{20}$ : el empleo de la sinalefa y la

17 «La poesía amatoria se vale de las dos lenguas, con predominio inicial del gallego, que pierde terreno después; en cambio, los panegíricos, epitafios, peticiones, obras de burlas o de maldecir, sátiras políticas, poesía moral y poesía religiosa prefieren el castellano. [...] No hay barreras infranqueables entre una y otra lengua: en el castellano de poetas habituados al gallego se deslizan, como era de esperar, galleguismos; a su vez el gallego de trovas compuestas por castellanos o andaluces abunda en castellanismos, aumentados frecuentemente por los copistas» (R. Lapesa, «El canciller Ayala», De Ayala a Ayala. Estudios literarios y estilísticos, Istmo, Madrid, 1988, pág. 9).

18 R. Lapesa, «La lengua de la poesía lírica desde Macías hasta Villasandino», Estudios de historia lingüística española, Paraninfo, Madrid, 1985, pág. 239.

$19 \mathrm{Si}$ bien es cierto que existen diferencias que separan los textos de ambos siglos, las semejanzas que los aproximan son, por otro lado, innegables: el uso de los mismos pies métricos (bisílabos, trisílabos y tetrasílabos, agudos y llanos, y pentasílabos llanos), el empleo de rimas consonantes en estrofas monorrimas, así como la estrecha relación entre significante y significado poético (como es el caso de la cántica ;Eya, velar! inserta en el poema berceano el Duelo de la Virgen).

20 «No existe en poesía medieval un plano gramatical-sintáctico distinto de su realización fonético-rítmica» (O. Macrí, Ensayo de métrica sintagmática [ejemplos del Libro de Buen Amor y del Laberinto de Juan de Mena], Gredos, Madrid, 1969, pág. 7). 
dialefa (según las exigencias métricas del verso), así como la mezcla indistinta de diversos tipos de versos (alejandrinos de dieciséis sílabas e introducción de formas estróficas como el zéjel y la octava de arte mayor) otorgaron nuevo ritmo al monolitismo del primer ciclo de la escuela del mester: «El alejandrino [...] se castellaniza en el mester juanruiciano y se acomoda fácilmente a los mismos tipos básicos (trocaico, dactílico y mixto) del octosílabo tradicional, pero regularizándose la proporción de los pies y el número de sílabas» ${ }^{21}$.

Dos ciclos poéticos diferenciados ${ }^{22}$, no sólo por los temas tratados, sino por la propia forma alterada, más abierta e innovadora, propia de un momento de cambio socio-cultural. Sin embargo, innovación no fue sinónimo de abandono de rigor poético; más bien al contrario, los nuevos poetas funden en sus composiciones originalidad, sátira y saber universal con estrofas poéticas vanguardistas ${ }^{23}$ bien rimadas, formadas por versos, cuya medida roza el perfecto isosilabismo. Las diferencias y las semejanzas entre los dos ciclos se diluyen en poetas herederos del mester a silavas contadas.

La evolución poético-estilística surgió de manera paralela a los grandes cambios fonéticos del castellano, a partir del reinado de Alfonso Onceno24: la estabilización de las estructuras silábicas, la aspiración procedente de [f] inicial latina y su pérdida, el proceso de monoptongación, además de otros cambios concernientes al consonantismo, como la diferencia fonológica entre $/ \mathrm{b} / \mathrm{y} / \beta /$, el ensordecimiento de /z/ y los primeros casos de yeísmo ${ }^{25}$, facilitaron la entrada de formas poéticas más innovadoras, tales como la acomodación del octosílabo, metro por excelencia del castellano coincidente con el nuevo ritmo silábico-acentual con sinalefa, o la introducción del molde poético de corte italianista:

La variedad de los esquemas métricos y la oscilación de las unidades estructurales, que se infiere del análisis de los textos del siglo XIV,

${ }^{21}$ O. Macrí, op. cit., pág. 44.

${ }^{22}$ La crisis motivó el relajamiento de la moral social y, en consecuencia, suscitó una actitud de crítica basada en la sátira y la parodia, estilo cada vez más distanciado de la finalidad didáctico-moralizante del primer ciclo del mester de clerezia.

${ }^{23}$ F. Rico («Entre el códice y el libro (notas sobre los paradigmas misceláneos y la literatura del siglo XIV)», Romance Philology, 51/2, 1997, págs. 151-169) ha puesto de relieve un rasgo singular de la literatura del siglo xiv: la proliferación de obras misceláneas, carentes de verdadera unidad. El rasgo que domina en todas ellas es el de la variedad y la mezcla de temas, materias y formas, tal y como acaece en el Libro del cavallero Zifar y el Rimado de Palacio, obra esta última considerada por este autor como el libro misceláneo por antonomasia: «[...] cuyas coplas 717-906 son un "desahogo lírico" constituido por dieciséis piezas compuestas en distintas fechas, sobre distintos temas y en distintos versos» (F. Rico, op. cit. pág. 165).

${ }^{24}$ «El área castellana oriental coincide en gran medida con los territorios controlados por don Juan Manuel a caballo de los siglos XIII y XIV [...] su mera existencia revela redes de comunicación compartidas que hicieron posible el tránsito y difusión de los rasgos lingüísticos» (I. Fernández-Ordóñez, La lengua de Castilla y la formación del español, discurso leído el día 13 de febrero de 2011 en su recepción pública, Real Academia Española, Madrid, 2011, págs. 59-60).

${ }^{25}$ M. Ariza, Fonología y fonética históricas del español, Arco/libros, Madrid, 2012, pág. 108. 
constituyen además el indicio de una inmensa experimentación formal y técnica. [...] en el mismo período en que se componían estos textos, Alfonso XI escribía la célebre cantiga «En un tiempo cogí flores», [...] texto amoroso-cortesano más antiguo que se conserva en lengua castellana (si bien con patentes hibridaciones léxicas) y la innovación métrica introducida por el soberano [...] debió de fomentar [...] la experimentación y el desarrollo del nuevo módulo métrico ${ }^{26}$.

Es en este marco de profundos cambios donde tiene cabida la formación letrada de Juan Ruiz y la composición de un hito histórico: el Libro de Buen Amor:

Tras aquella centuria firmemente estructurada, épica, con su literatura impersonal, el siglo XIV había traído la novedad de las notas individuales. [...] el Arcipreste de Hita infundía su propia exuberancia vital y su riente humorismo a cuantos tipos de aventuras podía imaginar la casuística amorosa, presentándose como protagonista de ellos ${ }^{27}$.

\subsection{Juan Ruiz, maestro en el arte de metrificar}

Dejando al margen las composiciones líricas de arte menor ${ }^{28}$ (Gozos de Santa María, coplas de las Serranas y otros cantares), el metro predominante en el poema narrativo del Arcipreste es la cuaderna vía: versos alejandrinos compuestos por hemistiquios heptasílabos u octosílabos agrupados en cuartetas monorrimas. El estudio de la métrica de los versos alejandrinos, así como su distribución en estrofas homogéneas o heterogéneas, ha sido objeto de atención por parte de los estudiosos, quienes, con la finalidad de reconstruir el texto, han consolidado las siguientes aportaciones, muchas de ellas contradictorias entre sí:

1) G. Chiarini ${ }^{29}$ y G. B. Gybbon-Monypenny ${ }^{30}$ aceptan el anisosilabismo como elemento característico de la obra juanruiciana: «Me parece que a veces Juan Ruiz se dejaba guiar por el oído, por el ritmo del verso, a costa de la cuenta exacta de las sílabas. Hasta de la cesura normal» ${ }^{31}$.

26 I. Tomassetti, Mil cosas tiene el amor. El villancico cortés entre la Edad Media y Renacimiento, Reichenberger, Kassel, 2008, págs. 74-75.

27 R. Lapesa, «El canciller Ayala», págs. 19-20.

${ }_{28}$ Como ya recogieron A. Zahareas y O. Pereira en su edición del Libro de Buen Amor (Libro del Arcipreste [Libro de Buen Amor], Akal, Madrid, 2009, pág. 171): «La forma más común de estos poemas líricos es el zéjel (o estribote) en que se combinan estrofas y estribillo: el poema comienza con un estribillo de dos, tres o cuatro versos que contienen el tema que ha de desarrollarse; siguen las estrofas rimadas, llamadas mudanza, cuyo verso final, vuelta, repite la rima del estribillo».

${ }^{29}$ G. Chiarini (ed.), Libro de Buen Amor, Riccardo Ricciardi, Milán/Nápoles, 1964.

${ }^{30}$ G. B. Gybbon-Monypenny (ed.), Libro de Buen Amor, Castalia, Madrid, 1988.

${ }^{31}$ G. B. Gybbon-Monypenny, loc. cit., pág. 78. 
2) J. Cejador ${ }^{32}$ cree que los hemistiquios de siete y ocho sílabas se distribuyen en versos alejandrinos con cuatro combinaciones posibles: $7+7,8+8$, $7+8$ y $8+7$, idea que sostienen Joset $^{33}$ y Blecua ${ }^{34}$, para quienes la fluctuación métrica podría haberse combinado con series de estrofas homogéneas $(7+7$ y $8+8)$. Blecua, por su parte, acepta que el autor tendía al isosilabismo, siempre y cuando sea posible la reconstrucción métrica de sus versos, ya que parece poco probable la enmienda de la presunta irregularidad en todos los casos. En esta misma línea, A. Zahareas y O. Pereira ${ }^{35}$ son partidarios de mantener la versificación de los manuscritos, manteniendo inalterados los versos híbridos de 7 u 8 sílabas, en tanto consideran la existencia de una tendencia métrica en el original: «En general, no se combinan hemistiquios de 7 y 8 sílabas. En cambio, los versos de 14 o 16 no parecen casos aislados ni arbitrarios ${ }^{36}$.

3) J. Corominas ${ }^{37}$, por el contrario, afirma que en la métrica de Juan Ruiz no hay «casos verdaderos de combinación en un mismo verso de dos hemistiquios con número de sílabas diferente» ${ }^{38}$. La regularidad silábica, por tanto, es un hecho motivado por el autor ${ }^{39}$, basada en la distribución equitativa de versos alejandrinos octosílabos y heptasílabos en cuartetas monorrimas homogéneas. La relación que media entre la secuencia rítmica y la temática a la que pertenece el contenido del texto se ajusta a la vinculación existente entre significante y significado de la materia poética ${ }^{40}$. De acuerdo con lo establecido por Corominas ${ }^{41}$, los versos alejandrinos octosílabos y heptasílabos no se encuentran de manera aleatoria, sino que se distribuyen equitativamente cumpliendo una función específica ${ }^{42}$ :

a) La alternancia de las estrofas escritas en versos heptasílabos con las escritas en versos octosílabos hace que, auditivamente, haya una ruptura en el ritmo del poema, resultando así una composición de mayor agilidad y viveza.

32 J. Cejador (ed.), Libro de Buen Amor, Espasa-Calpe, Madrid, 1963, pág. XXXI.

33 J. Joset (ed.), Libro de Buen Amor, Taurus, Madrid, 1990.

${ }^{34}$ A. Blecua (ed.), Libro de Buen Amor, Cátedra, Madrid, ${ }^{10} 2012$.

${ }^{35}$ A. Zahareas y O. Pereira, op. cit.

${ }^{36}$ A. Zahareas y O. Pereira, loc. cit., págs. 170-171.

37 J. Corominas (ed.), Libro de Buen Amor, Gredos, Madrid, ${ }^{2} 1973$.

38 J. Corominas, loc. cit., pág. 39.

39 Del mismo modo que en los cancioneros musicales: «la irregularidad y la excentricidad de algunos textos [...] se debe más bien a la corrupción o parcialidad de las fuentes que a una efectiva elección formal por parte de los autores» (I. Tomassetti, op. cit., pág. 135).

${ }^{40}$ D. Alonso, «Poesía española: ensayo de métodos y límites estilísticos», Obras Completas, IX: Poesía española y otros estudios, Gredos, Madrid, 1989, 9-524.

${ }^{41} \mathrm{~J}$. Corominas, op. cit.

42 Otro tanto hizo Menéndez Pidal (Textos medievales españoles. Obras completas de R. Menéndez Pidal, Espasa-Calpe, Madrid, XII, 1976, págs. 179-421) en su introducción a la edición de la Historia Troyana en prosa y verso, dedicando un estudio al cotejo de la métrica de esta obra de carácter polimétrico donde cada una de sus formas estróficas responde igualmente a una finalidad estética concreta. 
b) El cambio de tipo de verso da pie a la entrada de una nueva parte de la historia o al final de la misma, como se materializa en las Serranas, en que las introducciones en cuaderna vía correspondientes al discurso indirecto enmarcan la historia de cada aventura, expresada en discurso directo a través de versos de arte menor ${ }^{43}$.

c) La relación que media entre la secuencia rítmica y la temática a la que pertenece el contenido del texto, prueba de la maestría poética de Juan Ruiz, se ajusta a la teoría expuesta por Dámaso Alonso ${ }^{44}$ sobre la relación entre significante y significado de la materia poética ${ }^{45}$. Materiales, todos ellos, insertos en la tradición literaria medieval de mayor prestigio que hacen de esta obra de clerezia un compendio poético de saber universal: la autobiografía ficticia, el proemio o sermón, la colección de exempla, las teorías amatorias (que van desde el Ars amandi hasta las correspondientes al aristotelismo heterodoxo), los cantares de gesta (batalla de don Carnal y doña Cuaresma), las composiciones líricas trovadorescas profanas y religiosas e incluso sátiras insertas en la tradición goliardesca.

En repetidas ocasiones, Juan Ruiz se presenta como un gran poeta, de cuya maestría: tú non fallarás uno de trovadores mil (65d.). A partir de una lectura atenta del texto, parece poco probable admitir el anisosilabismo como rasgo propio de un texto caracterizado por su erudición e innovación, cuya pretensión es la de llegar a ser modelo del buen quehacer poético. La regularidad a sílavas contadas, derivada del aprendizaje de la cortesía y del buen rimar, persiste en este poema narrativo como ideal poético que, desde principios de la centuria precedente, se prolongará a lo largo de los siglos XIV y XV. Así entendido, los versos castellanos medievales se midieron tanto por imperativos poéticos como por las características lingüísticas de cada época.

La habilidad de romper con el monolitismo de la cuaderna vía de sus predecesores a partir de herramientas tales como la sinalefa, el encabalgamiento,

${ }^{43}$ F. P. Pla Colomer, «Pronunciación en el monte. Las serranas y la meta-parodia de Juan Ruiz», en E. Casanova y C. Calvo (eds.), Actes del 26é Congrés de Lingüística i Filologia Romàniques, W. de Gruyter, Berlín, 2013, págs. 710-721.

${ }^{44}$ D. Alonso, «Poesía española».

${ }^{45}$ La Historia Troyana y la cántica ¡Eya velar! de Berceo son las primeras muestras representativas en la historia de la literatura española portadoras del deseo del poeta de relacionar el significante y el significado de sus composiciones. Sirva como ejemplo el verso tú desfazes/muchas fazes del dezir 510 de Diego de Valencia, el cual: «crea una serie de cuatro troqueos en rápida sucesión que, junto a esa ristra de seis sibilantes, remachan el efecto arrollador de la muerte, acción puntualizada al mismo tiempo por la meliflua evocación de los rostros en un melódico octosílabo de tipo mixto/dáctilo + troqueo: "que fueron fermosas caras"» (L. M. Girón-Negrón, «"Muerte cates/ que non cates": el "Discor” 510 de Fray Diego de Valencia en el Cancionero de Baena», Revista de Filología Española, 82, 3․-4., 2002, pág. 260). De Jorge Manrique y la poesía relacionada con el tema de la muerte, afirma P. Salinas ( «Jorge Manrique o tradición y originalidad», Obras completas II, ensayos completos, Cátedra, Madrid, 2007, página 537): «[...] el tema ya llega a corporeizarse en fórmulas de estilo propias, que se corresponden con el sentido general de toda esta literatura mortal, el memento mori famoso». 
la sinafía o compensación métrica ${ }^{46}$, la inclusión de esquemas líricos estrechamente relacionados con la temática, así como la recreación de variedades sociolingüísticas castellanas (Serranas) y extranjeras (don Pitas Payas), justificarían, desde un punto de vista literario, la intención poética de Juan Ruiz de presentar un texto bien medido formado por versos alejandrinos regulares. Todo ello con la finalidad de conseguir un ritmo más ágil a partir de una combinatoria matemática, además de lograr un efecto literario simétrico excepcional que «[...] trasluce un espíritu lleno de apetencias vitales y de inagotable humorismo ${ }^{47}$.

\section{Aproximación fonético-métrica al libro del Arcipreste}

Desde una perspectiva filológica amplia, el conocimiento de la evolución del componente fónico castellano ${ }^{48}$ resulta indispensable para reconstruir adecuadamente la métrica de los versos y las rimas de los textos poéticos, en palabras de Malkiel ${ }^{49}$ : «A hard core of forms presumably reflects the unadultered personal usage of the poet, especially if the fairly reliable rime scheme and the distinctly less dependable metric pattern support the authenticity of a passage».

A partir de un estudio fonético-métrico, como herramienta filológica rigurosa, será posible describir las variantes lingüísticas empleadas en el proceso de creación de la palabra organizada rítmicamente:

Me parece vital insistir en que lo que las rimas reflejan sistemáticamente es la correspondencia con la pronunciación subyacente [...]. Lejos de reconstruir textos originales ideales para «corregirlos» y obtener con ello una lengua ideal falseada, como se ha objetado con razón en algún caso, parece hacedero inferir a través de la rima y métrica la relación oralidad-escritura en el pasado ${ }^{50}$.

46 J. M. Micó, «Sinafía y compensación en el Libro de Buen Amor», en G. Serés, D. Rico y O. Sanz (coords.), El «Libro de Buen Amor»: Texto y contextos, Universitat Autònoma de Barcelona, 2008, págs. 161-172.

${ }_{47}$ R. Lapesa, Historia de la lengua española, novena edición corregida y aumentada, Gredos, Madrid, ${ }^{9} 1981$, pág. 240.

48 «[...] una ley fonética resume un proceso, histórico o prehistórico para nosotros, cumplido en los sonidos de una lengua, cuyos puntos de partida y de llegada señala como jalones. Indica [...] un camino irreversible que se ha recorrido en un sentido determinado. Y este proceso [...] es un cambio regular que ha afectado a un sonido de una manera determinada, dondequiera que éste ocurriera» (L. Michelena, Lenguas y protolenguas, en Anejos del Anuario del Seminario de Filología Vasca «Julio de Urquijo», Xx, serie Obras completas de Luis Michelena, II, Diputación Foral de Gipuzkoa, San Sebastián, 1990 [traducción inglesa, Languages and Protolanguages, Universidad del País Vasco, Vitoria, 1999], pág. 65).

${ }^{49}$ Y. Malkiel, «Paradigmatic resistance to sound change. The Old Spanish preterit forms vide, vido against the background of the recession of primary - $d »$, Language, 36, 1960, pág. 317.

${ }^{50}$ M. T. Echenique, op. cit., pág. 49. 
La unión integral entre fonología evolutiva y métrica arrojará luz al presunto isosilabismo de la obra del Arcipreste, entendida, por tanto, como poema correspondiente al segundo ciclo del mester de clerezia caracterizado por la introducción del verso octosílabo, junto a formas estróficas propias de la lírica, cuya intención es la de crear una obra única y global inserta en el marco de la nueva estilística medieval.

\subsection{Apócope vocálica}

Contrariamente al mantenimiento en la oralidad de formas con apócope autóctona, como $<$ val $>$ ([bál' $\left.{ }^{{ }_{1} 1}\right]<$ VALET), articulación prolongada a lo largo de los siglos XIV y XV, como así lo demuestran la rima entre $<$ val $>$ y $<$ mortal $>$ de la composición lírica de Álvarez de Villasandino (15 bis, 2) y la rima entre $<$ mortal $>$, <mal $>$, <qual $>$ y $<$ val $>$ de la estrofa 7 del Rimado de Palacio, la apócope extrema era un rasgo lingüístico ya obsoleto ${ }^{52}$, por lo que "probablemente, una gran parte de los hemistiquios irregulares de 8 y 9 sílabas está motivada por las tendencias de los copistas a la recuperación de la forma sin apocopar» ${ }^{53}$, si bien es cierto que en lo relativo a los textos del mester de clerezia, la restitución de la apócope, ya autóctona ya extrema, podría haber servido como recurso métrico para regularizar la medida de los versos ${ }^{54}$.

Diego Catalán ${ }^{55}$ relacionó el fenómeno de apócope extrema con la estructura silábica castellana formada por un final duro, es decir, se habría recuperado la vocal final de palabra en el mismo momento en que se habrían perdido o vocalizado las consonantes duras que formaban el margen implosivo de las sílabas trabadas ${ }^{56}$.

${ }^{51}$ Coincido con D. Alonso («Temas y problemas de la fragmentación fonética peninsular») y Ariza (op. cit.) en que las grafías medievales indican la neutralización de $[b]$ y $[\beta]$ en posición inicial de palabra.

52 «[...] los finales consonánticos duros del castellano «koiné» concordaban con una sociedad basada en la coexistencia de castas bajo el cetro de los reyes de las tres religiones, a la vez que respondían al ansia de la cristiandad española por integrarse en la europea. En cambio la reacción contra la apócope extrema o la acomodación de los finales de palabra detonantes suponían una afirmación de las tendencias más profundas y duraderas de la fonología castellana» (R. Lapesa, «Contienda de normas lingüísticas en el castellano alfonsí», Estudios de historia lingüística española, Madrid, Paraninfo, 1985, pág. 211).

${ }^{53}$ A. Blecua, op. cit., pág. XCIV.

${ }^{54}$ M. Freixas, «La apócope en el Libro de Buen Amor», Moenia, 7, 2001, pág. 394, y O. Sanz, «Los usos de la conjunción, el artículo y la apócope por los copistas del Libro de Buen Amor: aplicaciones al texto», en G. Serés, D. Rico y O. Sanz (eds.), El Libro de Buen Amor. Texto y contextos, Centro para la edición de los clásicos españoles/Universitat Autònoma de Barcelona, Barcelona, 2008, págs. 173-188.

${ }^{55}$ D. Catalán, «En torno a la estructura silábica del español de ayer y del español de mañana», El español. Orígenes de su diversidad, Paraninfo, Madrid, 1989, págs. 77-104.

${ }^{56} \mathrm{C}$. Folgar, «Nuevas aclaraciones sobre la apócope extrema medieval a la luz de la 'jerarquía de la apócope'», en J. L. Ramírez y E. P. Velásques (eds.), La historia del español hoy. Estudios y perspectivas, Axac, Lugo, 2014, págs. 27-32, recoge la jerarquía de la apócope, diseñada por Sánchez Miret en 2001, para aplicarla al dominio de la lengua castellana medieval. 
[...] los finales consonánticos duros del castellano «koiné» concordaban con una sociedad basada en la coexistencia de castas bajo el cetro de los reyes de las tres religiones, a la vez que respondían al ansia de la cristiandad española por integrarse en la europea. En cambio la reacción contra la apócope extrema o la acomodación de los finales de palabra detonantes suponían una afirmación de las tendencias más profundas y duraderas de la fonología castellana y estaban a tono con el creciente sentimiento de la propia personalidad que hacía de Castilla portavoz de los pueblos cristianos de España ${ }^{57}$.

Por esta razón, a partir del Libro de Buen Amor la pérdida de vocal final de palabra tras consonante distinta a/-r/, /-s/, /-1/, /-n/, /-d/, /-ts/ se trató de un rasgo en detrimento que podría haberse mantenido gracias a la posible influencia ejercida por los mozárabes toledanos, razón por la que la forma apocopada $<$ nief $>$ del verso $671 \mathrm{c}$, atestiguada en el ms. $G^{58}$, queda justificada por la métrica del hemistiquio heptasílabo donde se inserta ${ }^{59}$ :

\section{VERSO}

1. estades enfriada más que nief' de la sierra (671c) < $\mathrm{NĚVE}$
ESCANSIÓN ACENTUAL

oóo òoóo/óoó ooóo

Los rimantes de la estrofa 385 del Libro de Buen Amor se documentan en el ms. $S$ con la vocal final <-e $>$ : <viene, detiene, atiene, tiene $>$; a diferencia del ms. $G$ que muestra la pérdida vocálica para dichas voces. Este resultado contrasta con el de la rima de la estrofa 737 con bien y quien, voces que nunca habían presentado una /-e/ final, ni siquiera paragógica, por lo que la apócope autóctona estaba consolidada en los sustantivos y en los adjetivos:

Los versos de Juan Ruiz constatan que la evolución del fenómeno de la apócope responde a las mismas tendencias articulatorias panrománicas: «1) la probabilidad de apócope es mayor si la vocal ocupa posición final absoluta que si se encuentra en posición final no absoluta [...], 2) la probabilidad de apócope es mayor si la consonante precedente es alveolar (o dental) que si es labial [...], 3) la probabilidad de apócope es superior si la vocal final sigue a una consonante simple que si sigue a un grupo consonántico».

57 R. Lapesa, loc. cit., pág. 211.

${ }^{58}$ Para una descripción detallada de la transmisión textual de la obra de Juan Ruiz: A. Blecua, «Juan Ruiz, Arcipreste de Hita. Libro de Buen Amor», en C. Alvar y J. M. Lucía (coords.), Diccionario filológico de literatura medieval española. Textos y transmisión, Castalia, Madrid, 2002, págs. 739-744 y «Los problemas textuales del Libro de Buen Amor», en Estudios de crítica textual, Gredos, Madrid, 2012, págs. 67-120.

${ }_{59}$ Cito todos los ejemplos del Libro de Buen Amor siguiendo la edición de J. Corominas (op. cit.), siempre en contraste con los manuscritos y el resto de ediciones. Para M. Freixas (op. cit. pág. 399) esta forma documentada en el manuscrito $G$ «se trata de un arcaísmo posibilemente motivado [...] por el registro plagado de fórmulas con el que el personaje que enuncia la frase, don Melón, se dirige a su amada, doña Endrina. Nieve es lo común en la obra». 
(2) Respondióle la dueña con mesura e bien $<$ BĔNE: «Buena mujer, dezidme quál es esse o quién $<$ QUĔM, que vos tanto loades, e quántos bienes tien $<$ TĚNET; yo pensaré en ello si para mí convién $<$ CONVĚNIT.»

(Libro de Buen Amor, 737)

El habla de los personajes rústicos del episodio de las Serranas, sin embargo, se caracteriza por el mantenimiento de formas apocopadas que, en la lengua estándar, habrían restituido ya la vocal final: «[...] las reducciones y deformaciones de me y te se dan con especial insistencia en boca de las serranas, como caracterizando su rusticismo» ${ }^{60}$. La articulación monosilábica de la forma de 3 . persona del singular <quier $>$ [kjér] queda justificada por la métrica del verso alejandrino heptasílabo de ritmo trocaico donde se inserta. Esta solución es la aceptada por J. Corominas ${ }^{61}$ y J. Joset ${ }^{62}$, en tanto que A. Blecua ${ }^{63}$, G. B. Gybbon-Monypenny ${ }^{64}$ y A. Zahareas y O. Pereira ${ }^{65}$ prefieren mantener la forma plena documentada en el ms. $S$ :

VERSO

3. el que no m'quier' pagar prïado le despojo (671c) $<$ QUAERIT
ESCANSIÓN ACENTUAL

oóo óoó(0)/ oóo òoóo

El decorum lingüístico, caracterizador tanto de los personajes que merodean la sierra como de aquellos integrados en la obra de Juan Ruiz (recuérdese la jerigonza extranjera de don Pitas Payas), habría sido el factor conducente al empleo de estas variantes en desuso:

En el reino de Toledo el lenguaje del Arcipreste de Hita conserva como arcaísmo popular algo de lo que antes había sido preferencia de señores y clérigos, y así usa todavía nief 'nieve', trax, dix, conbit [...], etc.; las reducciones y deformaciones de $m e$ y te se dan con especial insistencia en boca de las serranas ${ }^{66}$.

El caso de la apócope, por tanto, es reflejo de la realidad geográfica que sufría Castilla, cuyo margen de elección, como afirma Lapesa ${ }^{67}:$ «[...] obedeció en cada caso a razones de voluntad y prestigio». De esta forma, la decisión tomada por Alfonso X el Sabio, en cuyas obras se documenta decrecimiento

\footnotetext{
${ }^{60}$ R. Lapesa, Historia de la lengua española, pág. 247.

${ }^{61} \mathrm{~J}$. Corominas, op. cit.

62 J. Joset, op. cit.

${ }^{63}$ A. Blecua, op. cit.

${ }^{64}$ G. B. Gybbon-Monypenny, op. cit.

${ }^{65}$ A. Zahareas y O. Pereira, op. cit.

${ }^{66}$ R. Lapesa, Historia de la lengua española, pág. 247. También en M. Freixas, op. cit.

${ }^{67}$ R. Lapesa, «La apócope de la vocal en castellano antiguo: intento de explicación histórica», Estudios de historia lingüística española, Paraninfo, Madrid, 1985, pág. 197.
} 
progresivo de la apócope extrema, es un hecho que pone de manifiesto la introducción en el sociolecto culto de un rasgo lingüístico castellano popular.

(4) entendjmj $<$ ent $><<$ o $>>$ voluntad E memoria/las q $<$ ua $>$ les digo s'i buenas $\mathrm{s}$ ' $\mathrm{o}<\mathrm{n}>\mathrm{q}<\mathrm{ue}>\mathrm{t}<\mathrm{ra}>$ en [al] Alma conssolac' ${ }^{\text {io }}<\mathrm{n}>\&$ aluenga $<$ n $>$ la vida al cuerpo (fol. 1r).

Ca por el bue $<$ n $>$ entendjmje $<$ n $>$ to entiende onbre el bie $<$ n $>$ E sabe dello el mal (fol. 1v). E por end $<\mathbf{e}>$ vna $d<e>$ las petic'ion $<$ e $>$ s' $q<$ ue $>$ demando daujd a dios $p o<r>q<$ ue $>$ sopies'e la s'u ley fue esta (fol. 1v). $<\mathrm{INDE}$

E por ende s'igue la Raz'o $<$ n $>$ el dicho daujd en $\mathbf{o t}<\mathbf{r}><<\mathbf{0}>>$ loga $<$ r $>$ (fol. 1v).

ot $<$ r $><<$ o $>>$ s'i fuero $<$ n $>$ la pintura E la es'c $[<$ ri $>$ ]ptura \& las' ymagenes' $\mathbf{p}<$ ri $>$ merame $<$ n $>$ te falladas por rraz'o $<$ n $>$ (fol. 2 r).

onde yo de mj poq $<$ ui $>$ lla c'ienc'ia E de mucha E grand rrudez'a entiendo q $<$ ua $>$ ntos' bienes faz'e $<$ n $>$ perde $<$ r $>$ el alma (fol. 2 r). $<$ UNDE / GRANDE

$\mathrm{p}<$ ar $>$ a $\mathrm{mj}$ a $<\mathrm{n}>\mathrm{i}<\mathrm{m}>\mathrm{a}$ fiz' es'ta chica esc $<$ ri $>$ ptura en memoria de bie $<$ n $>$ (fol. 2r). $<$ FECIM

Las formas gráficas del texto en prosa conservado al inicio del manuscrito $S^{68}$, comúnmente aceptado por los investigadores como obra del propio Juan Ruiz, documentan la generalización de las formas plenas como <entendjmjento>, $<$ ende $>$, < onde $>$ y $<$ primeramente $>$, por lo que las formas con pérdida de vocal se reducen únicamente a los casos de apócope regular, como es el caso $<$ grand $>$ y $<$ fiz $>$, en contraste con la forma plena $<$ faze $>$. La totalidad de los editores han mantenido inalteradas las variantes gráficas de esta parte prosística del manuscrito $s$; parece coherente, por tanto, aceptar que en el sociolecto de mayor prestigio estaba prácticamente resuelto el proceso de recuperación vocálica tras final consonántico duro.

\subsection{Monoptongación del sufijo /-iello/}

Los textos poéticos del período que abarca los reinados de Fernando III hasta Sancho IV presentan en sus rimas regularidad articulatoria del sufijo [-jé.Ko] ${ }^{69}$.

${ }^{68}$ En aras de emplear un texto fidedigno, es decir, cuya forma respetara las grafías documentadas en el manuscrito salmantino, se emplea para citar la parte prosística del Libro de Buen Amor la edición diplomática llevada a cabo por Steven D. Kirby y Eric W. Naylor (Text and concordances of the Libro de Buen Amor [Gayoso, Salamanca and Toledo manuscripts], Hispanic Seminary of Medieval Studies, Nueva York, 2004).

${ }^{69}$ Para mayor detalle véase F. P. Pla «¿Regularidad fonética o nivelación morfológica en el paso de ie $>$ i? Fenómeno estudiado a la luz de la acomodación de los diptongos en el reinado de Alfonso Onceno», en A. Cabedo, M. J. Aguilar y E. López-Navarro (eds.): Estudios 
Soy de la opinión de que el Libro de Buen Amor es una obra representativa de una época de variación y cambio lingüístico, en la que todavía persistían variantes arcaicas, como es el caso de la pervivencia de la forma minoritaria [jé. Ko], justificada en la estrofa 314 por la rima con $<$ sello $>$, ya que la lectio $<$ syllo $>$ del manuscrito $S$ «es forma espuria introducida por el copista, para adaptarla a su rima, que ya había empezado a adulterar en los versos anteriores $\gg^{70}$ :

(5) Todos en el león ferién, e non poquiello: $<$ PAUCU + ĔLLU:

el jabalí sañudo dávale del colmiello, $<$ COLUMĚLLU, feriénlo de los cuernos el toro y el noviello; <NOVĚLLU el asno perezoso en él ponié su sello: $<$ SĬGILLLU

(Libro de Buen Amor, 314)

Es precisamente entre el reinado de Fernando IV y Alfonso Onceno el momento en que se documenta la apertura del proceso de monoptongación ${ }^{71}$ : «El diminutivo -illo, arraigado en Castilla desde tiempos remotos, pero rehusado por la lengua literaria, que prefería la forma arcaizante -iello, se generaliza ahora $\rangle^{72}$, como se deduce de la siguiente rima, en que una forma antigua como $<$ costiellas $>$ habría pasado a articularse como [kos.tí.Kas]:

(6) De parte de Valencia venían las anguillas ${ }^{73},<$ ANGUĪLLAS salpresas e trechadas, a grandes manadillas, daban a don Carnal por medio las costillas; $<$ CŎSTA + ĔLLAS las truchas de Alberche dávanle en las mexillas. $<$ MAXILLAS

(Libro de Buen Amor, 1105)

El episodio de las Serranas, por el contrario, revela pervivencia de dicha articulación, rasgo arcaico propio del discurso intrahistórico de las porqueiras. Sería preferible mantener gráficamente el diptongo <ie $>$ de este sufijo en los pasajes correspondientes a este episodio, como así lo documenta el ms. G, criterio

de lingüística: investigaciones, propuestas y aplicaciones, Universitat de València/Tecnolingüística, Valencia, 2013, págs. 303-311.

${ }^{70} \mathrm{~J}$. Corominas, op. cit., pág. 148.

71 «[...] insistí en que la reducción de -iello a -illo, temprana en castellano, se entendía mejor postulando un estadio en que el segundo elemento del diptongo era variable y por tanto proclive a ser asimilado por el entorno fónico. (Entre paréntesis, no creo muy probable la propuesta de Malkiel que supone influjo de los diminutivos -ito,-ico, -in, porque ¿quién asociaba con diminutivo palabras tan corrientes como castiello, cuchiello o siella?)» (E. Alarcos, «Reflexiones sobre el origen del sistema vocálico español», en A. Alonso, L. Castro, B. Gutiérrez y J. A. Pascual, eds., Actas del III Congreso internacional de historia de la lengua española, I, Arco/ libros, Madrid, 1996, pág. 19).

${ }_{72}$ R. Lapesa, Historia de la lengua española, pág. 248.

${ }^{73}$ Aunque en el manuscrito $G$ aparezca la variante gráfica <angiellas $>$, la rima de esta palabra con mexillas, procedente del latín MAXĪLLAS, asegura la pronunciación monoptongada. La totalidad de los editores optan por mantener la forma monoptongada. 
seguido por J. Corominas ${ }^{74}$ y J. Joset ${ }^{75}$ en sus respectivas ediciones:

(7) dam' çarciellos e heviella ${ }^{76}<*$ FIBĚLLA

de latón bien reluziente,

e dame toca amariella $<$ AMARĚLLA,

bien listada en la fruente,

çapatas fasta rodiella <ROTĚLLA;

e dirá toda la gente:

¡bien casó Menga Lloriente!» (Libro de Buen Amor, 1004)

En relación con los datos otorgados por las rimas de la obra del Arcipreste, en la parte prosística inicial se observa el empleo de la variante gráfica monoptongada de este sufijo en al forma $<$ poquilla $>$ :

(8) onde yo de mj poq<ui>lla c'ienc'ia E de mucha E grand rrudez'a entiendo q $<$ ua $>$ ntos' bienes faz'e $<$ n $>$ perde $<r>$ el alma \& al /. cuerpo (fol. 2r). $<$ PAUCU + ĔLLA

Todo ello corrobora la idea de que en la oralidad ya se había producido el proceso de cierre /-iello/ > /-illo/, mientras que podría haber pervivido en la pronunciación más popular, como se deduce de la voz de las serranas ${ }^{77}$.

\subsection{Estructura silábica: Proceso de regularización y contienda de variantes}

El castellano de la época de Alfonso Onceno se caracterizaba por la estabilización articulatoria de diptongos en sílaba tónica, ya que las vacilaciones

${ }^{74} \mathrm{~J}$. Corominas, op. cit.

75 J. Joset, op. cit.

${ }^{76}$ En este capítulo, las formas gráficas monoptongadas del manuscrito $S$ apuntan a una ultracorrección del escriba, cuyo usus scribendi parece alejarse del pretendido decorum lingüístico de Juan Ruiz. G. B. Gybbon-Monypenny (op. cit.), A. Blecua (op. cit.) y A. Zahareas y O. Pereira (op. cit.) prefieren mantener la variante monoptongada del manuscrito $S$.

77 De forma residual, el morfema /-iello/ habría llegado hasta la época de los poetas del Cancionero de Baena, como es el caso de la siguiente rima de Fray Diego de Valencia (cito por la edición de B. Dutton y J. González Cuenca, Cancionero de Juan Alfonso de Baena, Visor Libros, Madrid, 1993):

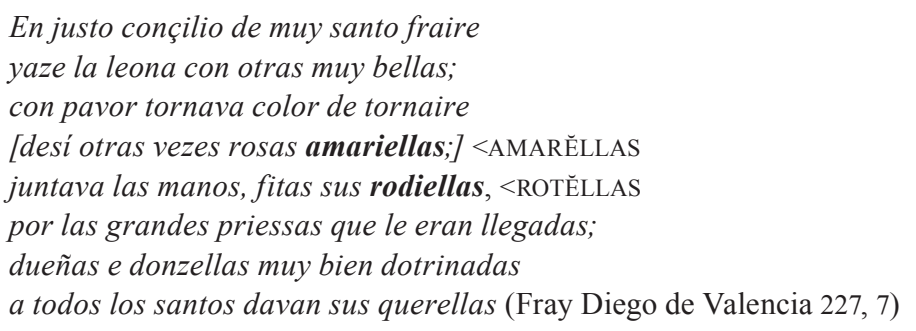

En la estrofa 9 de esta misma composición se hace rimar maravillas ( $<$ MIRABILǏAS) con sillas (<SĚLLAS), testimonio de la reducción del diptongo en /-illo/. 
únicamente se documentan en sílaba átona ${ }^{78}$; frente a ello, se constata el empleo de hiatos heredados del primer ciclo de la escuela del mester de clerezia: [tsi.én.tsja] ${ }^{79}$, [con.tsi.én.tsja] y [aw.ði.én.tsja], mantenidos en el castellano más prestigioso a lo largo de los sucesivos reinados Trastámara ${ }^{80}$ :

\section{VERSO}

9. El alcal.le, letrado e de buena cïencia $<$ SCIENTǏA usó bien de su oficio, guardó bien conciencia $<$ CONSCIENTǏA Estando assentado en la sü audiencia < AUDIENTǏA rezó él, por sí mismo escrita, tal sentencia < SENTENTǏA (347)

\section{ESCANSIÓN ACENTUAL}

ooóo oóo/ ooóo oóo oóo ooóo/ oóo ooóo oóo ooóo/ooó ooóo oóo ooóo/ oóo ooóo

Asimismo, Juan Ruiz modificó estructuras silábicas como herramienta para regularizar la métrica de sus versos, como es el caso de [des.tru.i.ðór], cuyo elemento semivocálico en coda silábica pasa a formar parte del segundo elemento de un hiato, en una estructura heterosilábica artificial. Esta contienda de formas persiste en la obra poética del Canciller Ayala y, en menor medida, en la lírica de cancionero, hasta su casi total regularización en la poesía cuatrocentista de Enzina:

\section{VERSO}

10. al uno e al otro eres destruïdor (416a) <ESTRUCTORE
ESCANSIÓN ACENTUAL

oóo ooóo/óo oòoó(o)

Desde las primeras obras del mester de clerezia la latinización del léxico era una de las normas que debía acatar el poeta, cuya finalidad era la de ofrecer un texto lo más cercano posible a la lengua de cultura. Por esta razón, en las obras de Gonzalo de Berceo se documentan formas como [re.ína] o [re.ís], voces que no corresponden a la realidad fónica de la época, pero que continúan en vigor en la tradición literaria, como se observa en el Libro de Buen Amor. Este rasgo no sólo se centra en la recuperación del léxico latinizado de la escuela del mester, sino que hay voces que presentan estructuras heterosilábicas cuando, en el nivel oral, ya se había producido la diptongación con anterioridad.

${ }^{78}$ Esta es la razón que justifica la articulación tautosilábica de $<$ cuerpo $>$ [kwér.po], procedente del latín CŎRPU, y $<$ buena $>$ [bwé.na], del latín BŎNA, en el siguiente texto: "aluenga $<\mathrm{n}>$ la vida al cuerpo $\mathrm{E}$ da $<\mathrm{n}>$ le onrra $\mathrm{co}<\mathrm{n}>$ pro \& buena fam[a] \}" (fol. $1 \mathrm{r}$ ).

${ }^{79}$ La escansión métrica de los versos permite deducir que la estructura heterosilábica se pronunció en la primera sílaba y no en las siguientes, ya que si en el verso 347a, en lugar de [tsi.én.tsja] (con escansión: ooóo oóo/ooóo oóo) se pronunciara *[tsjén.tsi.a], resultaría un pie métrico esdrújulo y, por tanto, un hemistiquio hipométrico: ooóo oóo/ooóo óo[o].

${ }^{80} \mathrm{Tal}$ es el caso de los versos de Pero López de Ayala: Es alta theología, sçïençia muy escura (Rimado de Palacio, 3a) o e olvidan conçiençia e la Santa Scriptura (Rimado de Palacio, 217d). Se citan los ejemplos según la edición de R. Lapesa, Rimado de Palacio. Esbozo de edición crítica por Rafael Lapesa Melgar con la colaboración de Pilar Lago (prólogo y estudio introductorio a cargo de Giuseppe Di Stefano), Generalitat Valenciana/Consellería de Cultura i Esport/Biblioteca Valenciana, Valencia, 2010. 
La información otorgada por el estudio de la métrica de los versos permite conocer el contenido fónico subyacente en las grafías de los textos prosísticos, por lo que, a partir de los versos de Juan Ruiz es posible interpretar con adecuación las grafías documentadas en el texto inicial en prosa. Las siguientes voces seleccionadas admiten articulación con hiato, procedente de la pérdida de consonante intervocálica latina o por el mantenimiento de la estructura silábica etimológica:

(11) las q $<$ ua $>$ les digo s'i buenas s'o $<$ n $>$ q $<$ ue $>$ t $<$ ra $>$ en [al] Alma conssolac' ${ }^{\prime} i 0<\mathbf{n}>$ \& aluenga $<$ n $>$ la vida (fol. 1r) $<$ CONSOLATIONE

E por end $<$ e $>$ vna $d<$ e $>$ las petic'ion $<$ e $>$ s' $\mathrm{q}<$ ue $>$ demando daujd a dios po $<$ r $>$ q $<$ ue $>$ sopies'e la s'u ley fue esta (fol. 1v) $<$ DEUS / LEGE Ot $<$ r $><<$ o $>>$ s'i diz'e salamo $<$ n $>$ en $<$ e $>$ l libro d $<$ e $>$ la sapienc'ia (fol. 1v) $<$ SAPIENTIA

E desq<ue $>$ esta $\left({ }^{\wedge} e\right)$ jnformada E jnstruyda el Alma (fol. 1v) $<$ INSTRUCTA

E estas' s'o $<$ n $>$ alg $<$ un $>$ as' d $<$ e $>$ las' rraz'on $<$ e $>$ s' por q $<$ ue $>$ s'o $<$ n $>$ fechos' los libros'\} d $<$ e $>$ la ley E d $<$ e $>1 \mathrm{~d}<\mathrm{e}>\mathrm{r}<\mathrm{e}>$ cho \& de castigos' E constu $<$ n $>$ br $<$ e $>$ s' $E$ de ot $<$ ra $>$ s' c'ienc'ias (fol. 1v - fol. $2 r$ ) $<$ SCIENTIAS

E por es'to es' mas' ap $<$ ro $>$ piada a la memoria $\mathrm{d}<\mathrm{e}>1$ alma $\mathrm{q}<\mathrm{ue}>$ es's'p<irit>u de djos (fol. 2r) <APPROPRIATA

ca mucho es' cruel q<ui $>$ en s'u fama menosprec'ia el d $<$ e $>r<e c>$ ho lo diz'e (fol. 2r) < CRUDELE

Bien sea intención cultista por parte del autor, bien sea rasgo lingüístico heredado de la escuela del mester, las voces seleccionadas del Prólogo en prosa de la obra del Arcipreste podrían interpretarse como hiatos etimológicos ([kon.so.la.tsi.ón], [dí.os] [sa.pi.én.tsja], [tsi.én.tsjas] ${ }^{81}$ y [apro.pi.á.ða]) o como estructuras heterosilábicas procedentes de la pérdida de consonante intervocálica latina ([lé.i] y [kru.él]), e incluso como artificio poético ([ins.tru.í.ða]).

\subsection{Formas de pretérito imperfecto de indicativo}

En el Libro de Buen Amor se documenta la generalización de la forma con hiato del pretérito imperfecto, aunque todavía en convivencia con la forma diptongada, como manifiestan las rimas de sus estrofas ${ }^{82}$ : en los últimos versos

${ }^{81}$ Mantengo la estructura heterosilábica en la primera sílaba de la palabra, en lugar de la última, como se desprende de la articulación de las estructuras silábicas, según el análisis métrico de los versos de Juan Ruiz.

${ }^{82}$ En F. P. Pla (Métrica, rima y oralidad en el Libro de Buen Amor, Quaderns de Filologia, Universitat de València, 2012, pág. 68) se recoge el número de estrofas en que se rima la forma con hiato y aquellas en que se rima la variante diptongada. Los resultados apuntan a 
de las coplas zejelescas correspondientes a los Gozos de Santa María (20-32) la variante con hiato está en rima con formas nominales como <Mixía $>$ :

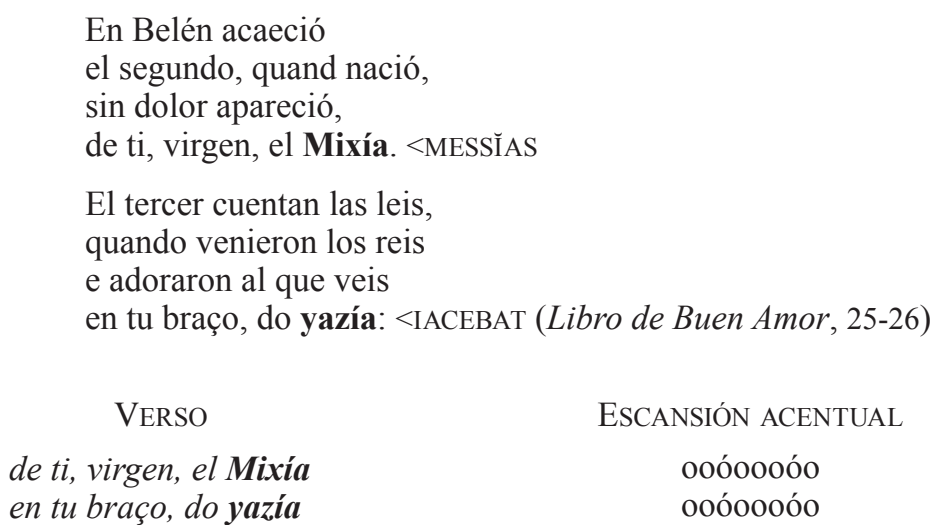

VERSO

de ti, virgen, el Mixía

ESCANSIÓN ACENTUAL

ooóoooóo

ooóoooóo en tu braço, do yazía

En contraste con ello, los manuscritos $S$ y $G$ atestiguan gráficamente la variante diptongada:

(13) Assí fue que los romanos ningunas leyes avién, $<$ HABEBANT e fuéronlas demandar a griegos que las tenién; <TENEBANT respondiéronles los griegos aquéllas non merecién $<$ MERESCEBANT nin las podrién entender, pues que tan poco sabién; $<$ SAPIEBANT

(Libro de Buen Amor, 47)

Del mismo modo, se observa la forma con diptongo, como única variante atestiguada en la parte escrita en prosa, razón por la que parece posible aceptar que este rasgo lingüístico todavía formaba parte del sociolecto más prestigioso:

(14) Ca diz'e $(<$ n $>$ ) s'ant gregorio q $<$ ue $>$ me-nos' firie $<$ n $>$ al onbre los' dardos' q $<$ ue $>$ ante son vistos' E mejor nos' podemos' g $<$ ua $>$ rda $<$ r $>$ $\mathrm{d}<\mathrm{e}>$ lo q $<$ ue $>$ ante hemos' visto (fol. $2 \mathrm{v}$ ) $<$ FERIEBANT

Cuarenta años después, en el Rimado de Palacio las formas de pretérito imperfecto se articulan, en posición de rima, con hiato [í.a], en tanto que en interior de verso la contienda de variantes es consecuencia de la intención de Ayala por regularizar sus versos. En el Cancionero de Baena todavía se confirman ciertas variantes en desuso del pretérito imperfecto con diptongo. Estos usos aparecen en el último tercio del siglo XIV en autores como Álvarez Villasandino o Francisco Imperial; asimismo, sobrepasan los umbrales del siglo XV, como

un empleo generalizado del pretérito imperfecto con hiato [í.a], frente a un número reducido de estrofas que presentan rimas con forma diptongada [jé]. Para un estudio más actualizado véase F. P. Pla, Letra y voz de los poetas en la Edad Media castellana, Tirant Humanidades, Valencia/Neuchâtel, 2014. 
se ve en la poesía de Álvaro de Luna. No se documenta ninguna forma con diptongo en posición de rima, por lo que podría tratarse de una licencia poética cuyo empleo servía para regularizar la métrica de los versos: que dezir me serié feo (Álvarez de Villasandino 41, 6); Tenié más: delante, una grand espada (Ruy Páez de Ribera 289, 6).

Desde la generalización de la variante con diptongo [jé], corroborada a partir de la métrica de los textos de Berceo y el Libro de Alexandre, hasta la consolidación articulatoria del hiato en época de los Reyes Católicos, el reinado de Alfonso Onceno representa la etapa donde tiene lugar la regularización de las estructuras silábicas, todavía en contienda con formas arcaicas de épocas anteriores ${ }^{83}$, resultado que confirma la teoría expuesta por Y. Malkiel ${ }^{84: ~ «[\ldots] ~ t h e ~ f a c t ~ r e m a i n s ~}$ that there occurred, after 1300, a sharp reversal of the preceding trend, leading, under conditions not yet investigated, to the wholesale withdrawal of -ié in favor of -ia».

\subsection{Articulación de F-inicial latina y aspiración}

Debido a la dialefa se constata pronunciación como articulación fricativa sorda $^{85}$ de la grafía $<\mathrm{f}->$, procedente de [f] inicial latina, como en $<$ fonda $>$, $<$ fablar $>\mathrm{o}<$ Fita $>$, topónimo documentado en los manuscritos $S$ y $G$ con $<\mathrm{f}>$, a excepción del verso $575 \mathrm{a}$, en que la grafía $<\mathrm{H}>$ de $<$ Hita $>$ podría explicarse como intromisión tardía del copista del manuscrito $S^{86}$ :

\section{VERSO}

ESCANSIÓN ACENTUAL

15. Amigos, vo a grand pena e so puesto en la fonda (650) $<$ FONDA

oóo óooóo/ ooóo ooóo

vo a fablar con la dueña, iquiera Dios que m'bien responda! (650) <FABLARE

Yo Joan Ruiz el sobre dicho acipreste de Hita (575a) (S) óoòoó oóo/óooóo oóo

${ }^{83}$ De esta manera podemos establecer una cronología que esboce el cambio evolutivo de la forma del imperfecto [-jé], cuyo punto más álgido se encontraría en el siglo XII hasta el reinado de Fernando III, y su progresiva desaparición culminaría en la época de los primeros Trastámara.

${ }^{84}$ Y. Malkiel, «Towards a Reconsideration of the Old Spanish Imperfect in -ia $\sim-i e ́ »$, Hispanic Review, 27, 1959, pág. 477.

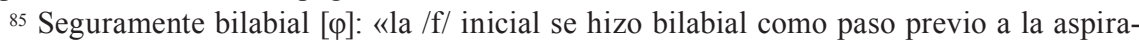
ción. Efectivamente, en una bilabial los elementos que intervienen son los labios, que solo se aproximan, la lengua está en reposo, por lo que basta un mínimo esfuerzo articulatorio en la laringe para que se produzca una aspirada» (M. Ariza, op. cit., pág. 135).

${ }^{86}$ En época del Arcipreste todavía se sentía como vulgar la articulación aspirada: «Sin éxito tan grande, se propaga también el paso de $f$-inicial a $h$, que aparece ya en algunos documentos oficiales; pero en la literatura sigue dominando la $f$, fazer, ferir, aunque en el Libro de Buen Amor aparezcan hato, hadeduro, Henares, heda 'fea' y algún otro ejemplo» (Lapesa, Historia de la lengua española, pág. 248). 


$$
\begin{array}{ll}
\text { Acipreste de Fita, dello primero fiz }(19 \mathrm{c})(S \text { y } G) & \text { ooóo oóo/óooóo ó(o) } \\
\text { que yo mucho faría por mi amor de Fita }(845 \mathrm{a})(S \text { y } G) & \text { oó óooóo/oóoó oóo }
\end{array}
$$

El habla de las porqueiras reviste sin embargo gran importancia por el abundante empleo de la grafía $<\mathrm{h}>$ inicial en representación de una articulación aspirada, todavía rechazada por el sociolecto más culto hasta su total aceptación en el reinado de Juan II y los Reyes Católicos, como así lo atestigua el Arte de poesía castellana de Juan del Enzina ${ }^{87}$.

[...] quando entre la una vocal y la otra estuviere la $h$, que es aspiración, entonces a las vezes acontece que passan por dos $\mathrm{y}$ a las vezes por una, $\mathrm{y}$ juzgarlo hemos según el común uso de hablar o según viéremos qu'el pie lo requiere, y esto también avrá lugar en las dos vocales sin aspiración.

Resulta, por tanto, pertinente mantener los testimonios con $<\mathrm{h}>$ inicial del manuscrito $G$, en aras del respeto al decorum lingüístico ${ }^{88}$ :

(16) la gaha, roín e heda ${ }^{89}$ : <FOEDA

«Alahé», diz, «escudero, (Libro de Buen Amor, 961)

dam `çarciellos e heviella <* FIBĔLLA (Libro de Buen Amor, 1004)

d'estaño, e hartas <FARTAS;

e dame halía (Libro de Buen Amor, 1036)

VERSO

la gaha, roín e heda

"Alahé», diz, "escudero

dam 'çarciellos e heviella
ESCANSIÓN ACENTUAL

oóooóoóo

ooóoooóo

óoóoòoóo
PIE MÉTRICO

Octosílabo mixto

Octosílabo dactílico

Octosílabo trocaico

${ }^{87}$ M. A. Pérez (ed.), Obra completa de Juan del Enzina, Biblioteca Castro, Madrid, 1996, pág. 18.

${ }_{88}$ Con la misma intencionalidad, parece ser que Juan Ruiz caracterizó el habla de otros personajes, como es el caso de la libre del ejército de don Carnal, quien articula como aspirada la voz $<$ hiebre $>$ [hjé.bre], documentada gráficamente con $<$ h $>$ en el manuscrito $G$ :

Vino presta al alardo, muy ligera, la liebre:

«Señor», diz, "a la dueña yo le porné la hiebre < FĚBRE

dalle he sarna e diviessos que de lidiar no l' miembre;

más querría mi pelleja quando alguno le quiebre.» (Libro de Buen Amor, 1090)

${ }^{89}$ Contrastemos este resultado gráfico con la forma empleada por Francisco Imperial en el siguiente verso (250,44): El fedor d'ellas, fijo, çiertamente. En este caso, a pesar de que la etimología no es la misma que heda, ambas sufrieron el proceso de aspiración y pérdida de [f-]; en cambio, en el caso de los serranos la representación gráfica apunta a una aspiración en contraste con el mantenimiento de la grafía $<\mathrm{f}->$ de Francisco Imperial. 


$\begin{array}{lll}\text { d'estaño, e hartas } & \text { oóooóo } & \text { Hexasílabo dactílico } \\ \text { e dame halía } & \text { oóooóo } & \text { Hexasílabo dactílico }\end{array}$

La parte inicial escrita en prosa muestra el empleo gráfico de $<\mathrm{f}>$ inicial para aquellas voces procedentes de [f] inicial latina. A partir de los datos obtenidos del análisis métrico de los versos del Arcipreste, se concluye que la grafía $\langle\mathrm{f}>$ de $<$ fablando $>,<$ fazer $>,<$ fechos $>,<$ falladas $>$ y $<$ firien $>$ encubre una pronunciación labial fricativa sorda, correspondiente al sociolecto de mayor prestigio:

(17) El p $<$ ro $>$ fecta $d<$ avi $>$ d por s' $<$ pirit $>$ u s' $<$ an $>$ to fablando a cada uno de nos diz'e en $<\mathrm{e}>1$ psalmo tric'esimo primo $\mathrm{d}<\mathrm{e}>1$ verso dez'eno q<ue $>$ es el q<ue $>$ p<ri $>$ mero sus'o escreuj (fol. 1r) $<$ FABLANDU

E pone lo $<$ e $>$ n la c'ela $\mathrm{d}<\mathrm{e}>$ la memoria por $\mathrm{q}<\mathrm{ue}>$ se acuerde $\mathrm{d}<\mathrm{e}>1 \mathrm{lo} \& \mathrm{t}<\mathrm{ra}>\mathrm{e}$ al cuerpo a faz'e $<\mathbf{r}>$ bue-nas obras' (fol. 1v) $<$ FACĚRE

E estas' s' $^{\prime}<\mathrm{n}>$ alg $<$ un $>$ as' d $<$ e $>$ las' rraz'on $<$ e $>$ s' por q $<$ ue $>$ s'o $<$ n $>$ fechos' los libros' (fol. 1v) $<$ FACTOS

E la es'c $[<\mathrm{ri}>$ ]ptura \& las' ymagenes' $\mathrm{p}<\mathrm{ri}>\mathrm{merame}<\mathrm{n}>$ te falladas por rraz' $^{\prime}<\mathrm{n}>\mathrm{q}<\mathrm{ue}>$ la memoria $\mathrm{d}<\mathrm{e}>1$ ome (fol. $2 \mathrm{r}$ ) $<$ FALLATAS

Ca diz'e $(<\mathrm{n}>)$ s'ant gregorio q $<$ ue $>$ me-nos' firie $<$ n $>$ al onbre los' dardos' $\mathrm{q}<\mathrm{ue}>$ ante son vistos' (fol. $2 \mathrm{v}$ ) < $<$ FERIEBANT

Del mismo modo que el estudio de la métrica de los versos ha puesto de relieve la aspiración como rasgo lingüístico propio de un registro más popular, rechazado por parte de Juan Ruiz, la parte escrita en prosa tampoco presenta el empleo gráfico de $<\mathrm{h}>$ para encubrir una articulación aspirada procedente de [f] inicial latina. Sin embargo, se constata la grafía $<\mathrm{h}>$ etimológica sin valor fónico, como es el caso de $<$ humana $>$ y $<$ deshonrra $>$ ([u.má.na] y [des.ón.ra]), como elemento culto de un dígrafo en $<$ catholica $>$ ([ka.tó.li.ka]) e incluso para marcar una dialefa o separar dos voces que terminan y empiezan por la misma vocal: <firme\#hedificio> ([e.ði.pí.tsjo]/[e.ði.pí.tsi.o]):

(18) Ante viene $\mathrm{d}<\mathrm{e}>$ la fraq $<$ ue $>$ z'a $d<\mathrm{e}>$ la natura humana $\mathrm{q}<\mathrm{ue}>$ es' en $<$ e $>1$ om $<$ n $>$ e q $<$ ue $>$ s'e no $<$ n $>$ puede es'capa $<$ r $>$ de pecado (fol. 1v) < HUMANA

E dando mala fama \& des'honrra E muchos' dan os' a los' cuerpos'(fol. 2r) $<$ DIS + HONORA

E porq $<$ ue $>$ toda buena obra es comjenc'o E fundame $<$ n $>$ to djos' \& la fe catholica (fol. 2v) $<$ CATHOLĬCA

do este no $<$ n $>$ es cimiento no $<$ n $>$ se puede faz' $\mathrm{e}<\mathrm{r}>$ obra firme $\mathrm{nj}<\mathrm{n}>$ fir-me hedific'io $($ fol. $2 \mathrm{v}$ ) $<$ AEDIFICIU 


\section{Conclusiones segund esta çiençia requiere}

La aplicación de los resultados obtenidos de la poesía al texto prosístico inicial de la obra de Juan Ruiz permite confirmar los rasgos fonético-fonológicos propios del sociolecto de mayor prestigio propios de la época del reinado de Alfonso Onceno: preferencia por las formas que presentan restitución de la vocal final apocopada en épocas anteriores, mantenimiento de estructuras heterosilábicas etimológicas, generalización de la variante con hiato [í.a] de pretérito imperfecto de indicativo, monoptongación del sufijo /-iello/ > /-illo/ y preferencia por la articulación fricativa sorda, ya bilabial $[\varphi]$ o labiodental [f], procedente de [f] inicial latina.

La pervivencia de variantes arcaicas junto a innovaciones fonéticas, rasgo propio del sociolecto de mayor prestigio, permite a Juan Ruiz diferenciar las formas lingüísticas de los personajes que pueblan el mundo plural del Libro de Buen Amor, desde las variantes sociolectales más cultas del propio autor, hasta aquellas relegadas al ámbito popular (las serranas) e incluso modalidades lingüísticas circundantes al castellano (la lengua de don Pitas Payas). La lengua del Arcipreste de Hita es, por tanto, reflejo de una época de revolución social y de cambio lingüístico característico de la primera mitad del siglo XIV, en que los arcaísmos más marcados se funden con innovaciones en un texto poético que revolucionó el mester a silavas contadas.

Por todo ello, convendría destacar y traer al primer plano la forma en que se presenta el poeta, autor de una obra total y universal, y que además es coherente con lo que hoy sabemos sobre los rasgos fónicos del castellano en época de Alfonso Onceno. En el Prólogo a su obra dice el autor: «E conpos'elo ot $<\mathrm{r}><<0>>$ s'i a da $<\mathrm{r}>$ alg $<$ un $>$ os' lec'io $<\mathrm{n}>$ \& muestra de metrifica $<\mathrm{r}>$ E rrima $<\mathrm{r}>$ E de troba $<r>$ / Ca trobas' E notas' \& rrimas' \& ditados'\& uersos' q $<$ ue $>$ fiz' conplidame $<\mathrm{n}>$ te $/$ Segu $<\mathrm{n}>\mathrm{d}$ q $<$ ue $>$ esta c'ienc[']ia Req $<$ ui $>$ ere» (Prólogo, fol. 2v).

En el Vocabulario español-latino, fechado hacia $1495^{90}$, Nebrija describe el arte como 'ciencia o oficio, ars, artis, techna, -ae'. A lo largo del siglo XVI, el término ciencia se recoge en los compendios lexicográficos como el 'conocimiento cierto de alguna cosa por su causa' y 'saber de cierta ciencia, [...] facultad' (Covarrubias, 1611: s. v. ciencia); mientras que durante el siglo XVII, esta voz adquiere nuevos significados hasta albergar un sentido enciclopédico, como se observa en la obra de 1645 de Salas (s. v. CIENCIA): 'ciencia, scientia, diciplina, ae; [ciencia] que las encierra todas, encyclopaedia, ae'. De esta manera, parece que el significado de los vocablos arte y ciencia se diluye en la lengua española antes de las obras de Antonio de Nebrija. En 1490, Palencia recoge en su Universal Vocabulario la noción de arte como 'preceptos et reglas ordenadas [...] que es virtud. Arte es dottrina o facultad auida por vso para obrar muy bien lo que por ella se faze', además de anotar la relación establecida entre las artes liberales

${ }^{90}$ Real Academia Española (ed.), Vocabulario español-latino de Antonio de Nebrija. Facsímil de la primera edición, patrocinado por la Asociación de Amigos de la Real Academia Española, Real Academia Española, Madrid, 1989. 
con el artificium y la dialectica, entendida como 'arte para discernir las causas delas cosas que aguza el entendimiento et distingue lo verdadero delo falso'. Dejando a un lado la tradición de las artes poéticas trovadorescas, Nebrija recoge en 1492 la métrica como relativo a arte: 'metrica ars, por el arte del metro', acepción que, junto a la de ciencia, recogen autores posteriores como Gravio (1551: 'fr., vne science'), Landuccio (1562: arte, sciençia o offiçio) o Decimator (1596: 'poetica, ae, vel poeticie, es ars conscribendorum versuum [...], arte de la poesía'). Del mismo modo ocurre con los compendios lexicográficos del siglo posterior, como es el caso de Covarrubias (1611: 'Es nombre muy general de las artes liberales y las mecánicas') hasta Stevens, quien en 1706 recoge en la voz arte: 'arte mayor, a sort of Spanish poetry, in which each verse consists of twelve syllables, or contains two verses of the lesser redondilla, each of which has six syllables. The rhyme in both alike' 91.

En lo concerniente a la obra del Arcipreste de Hita, Juan Ruiz parece presentar con orgullo su habilidad y maestría en el arte o ciencia poética, entendida como el conocimiento de reglas ordenadas que componen dicha arte o facultad, a saber: metrificar, rimar y trobar. A la luz de los datos del presente trabajo, se corrobora la perfección con la que se caracteriza la obra poética de Juan Ruiz, hecho que impide pensar que la cita extraída del Prólogo en prosa sea un juego retórico; todo lo contrario, es la reafirmación de un maestro en los preceptos segund que esta çiençia requiere.

Precisos, justos o cumplidos son tanto los versos alejandrinos como los de arte menor de Juan Ruiz, perfectamente isosilábicos y distribuidos en estrofas homogéneas de rima consonante, máxima expresión de la «Nueva Castilla» ${ }^{92}$ en su momento más copioso y exultante. La contundente afirmación del Arcipreste de Hita, así como la aplicación de los rasgos fónicos castellanos de la primera mitad del siglo XIV al Libro de Buen Amor permite corroborar el isosilabismo de Juan Ruiz, ejemplo de innovación y modelo poético del futuro desarrollo cultural castellano.

${ }^{91}$ Compendios lexicográficos extraídos de L. Nieto y M. Alvar, Nuevo tesoro lexicográfico del español (s. XIV-1726), Arco/Libros, Madrid, 2007 (s. v. ARTE y CIENCIA). Información contrastada con J. Corominas y J. A. Pascual, Diccionario crítico etimológico castellano e hispánico, Gredos, Madrid, 2006 (s. v. ARTE y CIENCIA).

${ }_{92}$ O. Macrí, op. cit., pág. 70. 